\title{
Reply to comments by Laffon et al.: Liver SUV versus stage in Hodgkin's lymphoma: the total amount of uptake may play a role in the inverse relationship
}

\author{
Agostino Chiaravalloti • Orazio Schillaci
}

Received: 21 September 2014 / Accepted: 23 September 2014 / Published online: 22 October 2014

(C) Springer-Verlag Berlin Heidelberg 2014

Dear Sir,

We read with great interest the letter from Laffon et al. [1] in which the authors refer to a recently published paper of our group that evaluates the factors affecting 2-deoxy-2- $\left({ }^{18} \mathrm{~F}\right)$ fluoro-D-glucose $\left({ }^{18} \mathrm{~F}\right.$-FDG) uptake in the liver and mediastinum during chemotherapy (CHT) in Hodgkin's lymphoma (HL) [2]. Laffon et al. suggest that the total amount of uptake in malignant tissues of cancer patients may play a role in the reduction of ${ }^{18} \mathrm{~F}-\mathrm{FDG}$ uptake in the liver at staging in HL (as shown in the report previously cited) $[2,3]$. For this reason, the authors suggest that the measurement of the total ${ }^{18} \mathrm{~F}$-FDG that is irreversibly trapped in a pathological tissue (as measured by a formula suggested by Laffon et al. [3]) could help in the explanation of this phenomenon and could be useful when evaluating positron emission tomography/computed tomography (PET/CT) scans of patients with cancer.

We agree with the hypothesis of Laffon and colleagues. We performed a further analysis of the data already published [2], and here we report a graphical representation of the relationship between the maximum standardized uptake value $\left(\mathrm{SUV}_{\max }\right)$ in the mediastinum and the stage of the disease (Fig. 1) that led to results similar to those observed in the liver [2]. In particular, in our study cohort, the $\mathrm{SUV}_{\max }$ in the mediastinum is significantly related to the extension of HL according to Ann Arbor criteria with a lower $\mathrm{SUV}_{\max }$ in the mediastinum being related to a higher stage of the disease ( $p=$ 0.0385 , Fig. 1) [2]. In agreement with Laffon et al., we can conclude that when a tissue shows an intense tracer uptake, the

A. Chiaravalloti $(\triangle) \cdot$ O. Schillaci

Department of Biomedicine and Prevention, University Tor Vergata,

Viale Oxford 81, 00133 Rome, Italy

e-mail: agostino.chiaravalloti@gmail.com

O. Schillaci

IRCCS Neuromed, Pozzilli, Italy

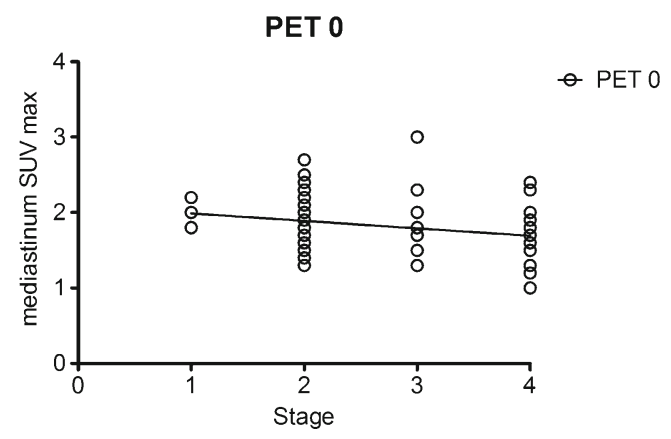

Fig. 1 Graphical representation of the linear regression analysis that investigated the relationships between mediastinum $\mathrm{SUV}_{\max }$ and the stage of HL. Further details can be found in the text and in reference [2]

amount of tracer available to another tissue is reduced (to be specific, the circulating ${ }^{18} \mathrm{~F}-\mathrm{FDG}$ in the blood as detectable by means of mediastinum $\mathrm{SUV}_{\max }$ ) [4]. We would like to thank Laffon et al. for their detailed comments and suggestions that have greatly improved the results of our study.

\section{References}

1. Laffon E, de Clermont H, Lamare F, Marthan R. Liver SUV versus stage in Hodgkin's lymphoma: the total amount of uptake may play a role in the inverse relationship. Eur J Nucl Med Mol Imaging 2014. doi:10.1007/s00259-014-2925-1.

2. Chiaravalloti A, Danieli R, Abbatiello P, Di Pietro B, Travascio L, Cantonetti $\mathrm{M}$, et al. Factors affecting intrapatient liver and mediastinal blood pool (18)F-FDG standardized uptake value changes during ABVD chemotherapy in Hodgkin's lymphoma. Eur J Nucl Med Mol Imaging 2014;41:1123-32. doi:10.1007/s00259-014-2703-0.

3. Laffon E, de Clermont H, Lamare F, Marthan R. Estimating the amount of FDG uptake in physiological tissues. Nucl Med Biol 2014;41:717-20.

4. Boellaard R. Standards for PET image acquisition and quantitative data analysis. J Nucl Med 2009;50:11S-20S. 